\title{
MODERATING EFFECT OF INNOVATION ECOSYSTEM ON KNOWLEDGE ENTREPRENEURSHIP AND INNOVATION PERFORMANCE OF MANUFACTURING FIRMS IN KENYA
}

\author{
${ }^{1}$ Isaac Muiruri Gachanja, ${ }^{2}$ Stephen Irura Nganga, ${ }^{3}$ Lucy Maina Kiganane \\ ${ }^{1}$ Ph.D. Student; Karatina University \\ ${ }^{2}$ Associate Professor of Entrepreneurship; Karatina University \\ ${ }^{3}$ Senior Lecturer, Entrepreneurship; The Cooperative University of Kenya \\ Email : ${ }^{1}$ igachanja@gokeglobal.org, ${ }^{2}$ inganga@gmail.com, ${ }^{3}$ lucynmaina09@gmail.com
}

\begin{abstract}
Purpose: Examine the moderating effect of Innovation Ecosystem (IE) on the relationship between Knowledge Entrepreneurship (KE) and Innovation Performance (IP) of manufacturing firms in Kenya.

Design/methodology/approach: The study was anchored on the complexity theory. Mixed method research was applied which utilized cross-sectional design. The target population was 828 manufacturing firms. Purposive and stratified random sampling was used to determine a sample size of 115 firms.

Findings: The study found that IE has a great moderating effect between KE and IP in manufacturing firms in Kenya. Collaboration and networking between industry, research organizations and universities should be strengthened to promote IP and increase the competitiveness of firms.

Research limitations/implications: The number of sample is relative small compared with the population.

Practical implications: Result of this research shows that Innovation system is one of the most important things in resulting Innovation performance.
\end{abstract}

Originality/value: This research is original because this research conducts in Kenya and there is no similar research in Kenya.

Paper type: Research paper

Keyword: Collaboration, Competitiveness and Knowledge leakage

Received: February $17^{\text {th }}, 2020$

Revised: August $4^{\text {th }}, 2020$

Published: September $30^{\text {th }}, 2020$

\section{INTRODUCTION}

The emerging turbulence in firms has cast doubts on their sustainability of the current business models. Consumers are becoming more directly involved, technology is continually becoming the core of innovation and ecosystems are re-defining the types of innovativeness (Majava, Leviäkangas, Kinnunen, Kess, \& Foit, 2016).This calls for new solutions to handle the ever raising disruptions. The solutions to this menace lie in embracing Innovation Performance (IP).

Kenya has developed a comprehensive innovation policy framework, but the relationship between research institutions and industry still remains disjointed. This has been brought about by multiplicity of new institutions that have become a barrier to knowledge sharing and thus firms are shying away from intense collaboration with research institutions and universities which has led to declining knowledge absorption, creation and diffusion which are key components of innovation performance (Dutta, Lanvin, \& Wunsch- 
Vincent, 2015). Knowledge-based institutions are also not actively involved yet they are key sources of information for innovation. Linkages within the innovation system are weak and the manufacturing sector has the highest abandoned innovation activities at about 40\% (Atandi, Bwisa, \& Sakwa, 2016). There has also been the failure of incorporating local knowledge in the innovation process (Sambuli \& Whitt, 2017).

There are also several gaps that have not been addressed by previous researchers in this area of study. Previous researchers have not managed to unravel the puzzle of how to transform knowledge into innovation output that improves competitiveness in the manufacturing sector. The complexity of blending internal and external knowledge and reconfiguring new insight for greater IP has also not been adequately addressed. The quagmire of striking a balance between sharing knowledge, guarding against knowledge leakages, diffusion of tension and mistrust that emanates from competition while interacting with the operating ecosystem to improve IP has not been resolved. The study attempted to address these gaps.

The purpose of this study is therefore to investigate the interrelationships between Innovation Ecosystem (IE), Knowledge Entrepreneurship (KE) and IP in Kenya manufacturing enterprises in Kenya. The main objective is to examine the moderating effect of IE on KE and IP of manufacturing firms in Kenya. The objective was achieved by hypothesis testing. The null hypothesis stated that IE has no significant influence on the relationship between KE and IP of manufacturing firms in Kenya.

Innovation Performance is the level of increase in novel products, creative processes, development of new ventures and discovery of new markets that contributes to value growth and sustainable development. It is the degree and the rate at which enterprises innovate in terms of new products, processes, management and market Andreeva \& Kianto (2011) in comparison with the competitors (Zelaya-Zamora \& Senoo, 2013). Innovation Performance raises the competitiveness of firms by putting them in a strategic advantage to navigate into the future successfully.

The measure of IP in this study is thus arrived at generating the product of Innovation Output (IO) and Innovation Efficiency. This can be expressed mathematically as;

$\mathrm{IP}=\sum_{\mathrm{t}}^{\mathrm{n}}=\{($ Innovation Ouput) $\times$ (Innovation efficiency) $\}$ which can also be expressed as;

$\sum_{\mathrm{t}=3}^{\mathrm{n}}\{(\mathrm{Inp}+\mathrm{Pa}+\mathrm{Nip}+\mathrm{Ne})(\mathrm{SG})\}$ where Inp is the sum of the increased new product, Pa is patents acquired, Nip is the new innovation process, Ne is the new enterprises all as result of innovation, SG is the percentage sales growth rate brought about by innovation, $\mathrm{n}$ is the number of years and $\mathrm{t}=3$ is the time series of the three years from which data on IP was collected. Lau \& Lo (2015) contends that IP is measured as a percentage of new products commercialized in relation to all products of a firm and a period of three years is highly regarded because it depicts a firm's relative strength in innovation while sales growth rate indicate the level of market impact, advantage and financial success. It is worth noting that the key input in innovation activities is human resource which a firm can leverage on by tapping on the immense possibility of KE.

There are sveral definitions of KE that have been fronted. Senges (2007) defined KE as the ability to recognize viable opportunities in intellectual resources and exploit them innovatively through the development of intellectual venture. It is also a type of intellectual entrepreneurship that focuses on improving research through the input of knowledge (Abosede \& Onakoya, 2013). Knowledge entrepreneurship is, therefore, the ability to utilize new information acquired through learning to identify and seize up opportunities that address the needs of society.

The measure of KE is derived from by Brem (2011) model which was later improved by (Senges, 2007). The model depicts the organization setting factors which include; leadership, culture, communication and organization learning that influences KE and ultimately innovation. This paper expands communication to encompass information and technology.

There are several definitions that have been advanced in an attempt to understand IE. Poikola, Kola, \& Hintikka (2011) are of the opinion that it is the functioning interdependency among partners with dynamic interaction between different actors within a given locality. Leavy (2012) urges that it is the integration of solutions from combined efforts of multiple partners. Innovation ecosystem is therefore the operating environment in which firms have collaborative networks with the different stakeholders for cooperation to improve IP.

Innovation Ecosystem has been measured in a number of ways. To begin with, it can be measured by the level of networking among participants, universities, research institutions and government agencies (Uzkurt, Kumar, Semih Kimzan, \& Eminoğlu (2013). This underscore the importance of networking in IE. Majava et al. (2016) posited that the parameters for IE are; accelerators, incubators, business services and trade organization support which provides for technology spill over and infrastructural economies. These parameters were adopted in the proposed study because they capture the essential ties within entities in manufacturing IE such as the role of government, financial institutions, innovation and technology markets, Universities, research and innovation institutions. However, the value of such collaborations and the level of operational efficiency IE brings have not been adequately explored in manufacturing sector in Kenya. 


\section{METHODOLOGY}

Mixed method research was applied because it allowed for triangulation. Cross-sectional design was used to help in making observations on characteristics that exist within the manufacturing sector.The target population was the 2484 middle level management within the 828 manufacturing firms as listed in the Kenya Association of Manufacturers' (KAM) directory of year 2017/2018.

The sampling strategy used was multi stage sampling strategy which included; purposive and stratified random sampling. Purposive sampling was used to select the major industrial counties in the country. This is because geographical area concentration of manufacturing firms provides an ecosystem for accessing knowledge, diversity in organization culture, high rate of new technology adoption and wide networks for collaboration (Dvir \& Pasher, 2004). These regions are also suitable spatial units for knowledge acquisition, accumulation, utilization and innovation transfer because they attract investments and talents (Majava et al., 2016). The major industrial counties which were sampled are 7 and they include: Nairobi, Mombasa, Kisumu, Nakuru, Kiambu, Machakos and Uasin Ngichu because they have the largest number of manufacturing firms in the country. Stratified random sampling was then used to sample firms in selected Counties. This is because it provides for proportionate representation from the different subgroups in a population and allows for inclusion of specific characteristics in a sample (Creswell, 2014). The sampling design therefore allowed for firms to be sampled from the various manufacturing sub-sector according to the relative numeric strength.

Purposive sampling was then used to sample the respondents. This enabled the researcher to select the key respondents with the information required with respect to KE, IE and IP. The respondents were the heads of operations, innovation and marketing because these are the key personnel who have the responsibility of knowledge management, contextual adaptability and promotion of innovation performance in their firms.

The sample size determination was through an application of scientific formula which will provide an objective representation of the target population. The formula to be applied is Yamane (1967) formula which states that; $\mathrm{n}=\mathrm{N} /(1+\mathrm{N}($ 『e $) \rrbracket \wedge 2)$

Where $\mathrm{n}$ is the sample size, $\mathrm{N}$ is the target population and e the level of precision which in this case is $5 \%$ which is the acceptable level of significance in social science research. The application of the formula leads to; $\mathrm{n}=\frac{2484}{1+2484(0.05)^{2}}=344$

Proportionate representation from each county was provided for to eliminate bias in selecting firms from the same area. This was done by dividing the sample size of 344 by the 3 respondents per firm to determine the number of firms to be sampled which was115. The number of firms to be sampled per county was total number of firms in the county divided by the total number of firms in the sampled counties and then multiplied by the required total sample size of the firm derived from the Yamane (1967) formula. The inclusion of all manufacturing sub-sectors was a form of data triangulations. Simple random sampling from the different manufacturing sub-sectors will then be used to obtain the number of firms per sector and kept proportional to the sizes of the sub sector.

The researcher collected primary and secondary data using both quantitative and qualitative methods. This was meant to improve accuracy, produce a holistic view and to hedge off against the biases of single methods (Denscombe, 2008). Data was collected using interview schedules, questionnaires and checklists. Convergent, discriminat, content and criterion related validity were used to ascertain the credibility of the research procedure. Reliability was tested using internal consistency technique.

\section{RESULTS AND DISCUSSION}

The questionnaires received and filled up were 295 against 345 issued representing a response rate of $86 \%$ from 101 firms out 115 firms representing $88 \%$ of the firms sampled. The dependable variable of the study was IP which was derived from the product of innovation output and innovation efficiency. The majority of manufacturing firms had zero IP as indicated in figure 1.

This implies that most of the innovation activities in manufacturing firms did not translate into IP. This means that innovation output did not necessarily results into improvement in sales growth rate as a result of innovation. It explains the challenge that manufacturing firms in Kenya are undergoing thus losing their competitiveness at local, regional and global market.

The other step was a comparison of IP in the 12 subsectors of the manufacturing sector. Crosstabs descriptive analysis was used to examine the IP levels across the subsectors. The subsector with the highest IP was the food and beverages subsector as indicated in figure 2. 
The highest IP in the food and beverages subsectors implies that innovation intensity is important in raising the overall IP levels. This is because despite the plastics and rubber subsectors having the highest innovation output, the food and beverages subsector had the highest innovation intensity emerged top in IP. Firms should therefore not only focus on raising the innovation output, but also innovation intensity for higher levels of IP. It is therefore important for firms to diversify their innovation activities across the various types of novelties to spread the risks that come with concentration on a single type of novelty.

Knowledge Entrepreneurship is the independent variable in the study. The antecedents of KE were Organisation Learning (OL), Organisation Culture (OC), Leadership and Information, Communication and Technology (ICT). The sum of the oberved measure of each antecedent was obtained and the sums agregated to form a compsite value of the latent variable KE.

The comparison of how the different subsectors performed in terms of KE was also carried out using explore descriptive statistic. The subsector which showed a high level of variance on KE score was metal and allied as indicated in figure 3 .

This implies that there was indifference as to whether KE promoted innovation in the firms within the metal and allied subsector. It means that $\mathrm{KE}$ was enhanced in some firms within the subsector to promote innovation while it was not the case with other firms.

The other factors that were raised that affect KE includes; availability of resources, size of the company, quality of information, competation, commercialization, networking, trust levels, communication systems, knowledge management, adaptability, strategy and knowledge levels. Most of these factors are similar to the different parameters for the various antecedents of $\mathrm{KE}$ as adopted in the study. The composite value of KE was arrived at addding up the aggrgate values of OL, OC, leadership and ICT.

Reliability test was conducted to find the stability of the observed items of each measure in every parameter in providing similar outcome in repeated trials on latent variable KE. Internal consistency technique was used to show the extent to which the procedure applied assessed the same characteristics. Different respondents from the same firm will provided for data triangulation which enabled assessment of both individual reliability of each parameter and the composite reliability of each variable. The reliability test produced Cronbach's Apha of 0.901, 0.898, 0.905 and 0.901 for OL, OC, leadership and ICT respectively as indicated in table 1.

The values were all above the recommeded threshold of 0.7 . It means that the scale used to measure $\mathrm{KE}$ is reliable and can replicate such outcomes in other trial. The finding is consistent with (Alegre, Lapiedra, \& Chiva, 2006) who found that the Cronbach's alpha of the measures of latent variable should be more than 0.7 .

The parameters of KE were first regressed with IP and then the aggregate value of KE with IP. The relative strength of each of the parameters was determined in terms of their value of $\mathrm{R}$ square. The parameters arranged in terms of great strength to least are OC, leadership, ICT and OL as indicated in table 2.

The $\mathrm{R}$ square for each of the variable is above 0.5 meaning that each one of them had immense contribution to IP at above $50 \%$ although at different extent. This implies that the contrast of KE was properly constituted with regard to their relationship with IP.

Further regression analysis was conducted to find the significance of each of the parameters on IP. All the parameters apart from OL had $\mathrm{P}$ values of less than 0.05 as indicated in table 3 .

This implies a rejection of null hypothesis on OC, leadership and ICT and acceptance of the alternative hypothesis that the three parameters have significant influence on IP. It was also observed that OL did not have a significance influence on IP since the $\mathrm{P}$ value was 0.234 which is above 0.05 . This is not surprising given that OL had the least contribution in IP.

Linear regression was also carried out to determine the extent to which KE influences IP of manufacturing firms in Kenya. The coefficient of regression between of KE and IP was then done and the results showed a positive value of 0.154 as indicated in table 4 .

The positive value implies that there is a direct relationship between KE and IP. It therefore means that as KE increases so do IP and vice versa. The results mean that IP is expected to increase by 0.154 when KE increases by a unit holding IE constant. This lead to the development of the first model which can be expressed as; , where and is the error term thus. This means that IP is expected to increase by 0.154 when KE increases by a unit holding IE constant.

Regression analysis between of KE and IP was also done to establish the R square value. The results produced an R square value of 0.675 as shown in table 5 .

The R square value of 0.675 is equivalent to $67.5 \%$. This implies that a huge proportion of change in IP $(67.5 \%)$ is brought about by KE. Manufacturing firm in Kenya should therefore enhance KE for increased IP.

The findings are consistent with Chen, Lin, \& Chang (2009) who found that KE bring about competitive advantage of a firm thus significantly influencing its IP. Zhang, Di Benedetto, \& Hoenig (2009) also found that knowledge utilization is a strong predictor of IP because it hedges off against the challenges

Moderating Effect Of Innovation Ecosystem On Knowledge Entrepreneurship And Innovation 
of breakthrough. The findings also concurs with those of Rosnani, Soaib, \& Babak (2010) who fond that KE enables a firm to respond and seize up opportunities leading to IP. Sotarauta \& Pulkkinen (2011) also found that KE enhances commercialisation which increases the level IP. The findings are also consistent with those of Cao \& Zhao (2013) who found that KE is paramount in commercialization of innovation which enhances IP.

\section{A. Normality test of KE and IP}

The normality test of data for both KE and IP was done through the levene's statistics. The p value was zero which is less than 0.05 hence there is a difference between KE and IP as indicated in table 6

This implies that the KE and IP are normally distributed meaning that the data collected was homogenous.

The moderating variable of the between KE and IP was IE. The parameters for measuring IE were; presence of accelerators and incubators within the firm locality, availability of business services, trade organization support and technology spill over in the industry from universities and other research institutions, networking within the firms in the industry and infrastructure that support business operations. The value of IE was obtained by aggregating the sum of the score of each measure. The responses were captured in a likert scale which had six items with a scale of 1 to 5 and thus the expected maximum score was 30. The score on each of the item was then added up to form the composite value of IE in each firm.

The comparison of how the different subsectors performed was carried out using explore descriptive statistic. The subsector which showed a high level of variance on IE score was metal and allied as indicated in figure 4

This implies that there was indifference as to whether IE promoted innovation in the firms within the metal and allied subsector. It means that IE was enhanced in some firms within the subsector to promote innovation while it was not the case with other firms.

The respondents were asked to give the factors they felt affects the operating environment on which innovation occurs. The listed factors in descending order are; networking, statutory and regulatory requirements, infrastructure, government policy, rate of technology adoption, competition, taxation, financing, knowledge sharing platforms, treaties and barriers of imports, training opportunities, macroeconomic stability, accreditation and certification procedures. The other factors that were mentioned includes; protection of patents, incubators, customer and supplier relationship, quality of human resource, university industry linkages, stakeholder satisfaction, trade fairs, industry leadership, dissemination of research findings, cost of doing business, trade associations and safety. It is therefore observed that there is a wide range of factors that contribute to innovation ecosystem.

Reliability test was conducted on the measuring scale of IE to determine its stability in providing similar outcome in repeated trials. The reliability test produced Cronbach's Apha of 0.896 for the six measures for IE. The value is above the recommeded threshold of 0.7. It means that the scale used to measure IE is reliable and can replicate such outcomes in other trial. The finding is consistent with Alegre et al. (2006) who found that the Cronbach's alpha of the measures of latent variable should be more than 0.7.

The first step was to run a linear regression between the Parameters of IE and IP without KE. The results indicate that all the parameters of IE had an R square of between 0.610 and 0.711 as indicated in table 7.

This implies that all the parameters of IE made substantial contribution to IP. It therefore means that IE is paramount in determining IP.

Linear regression was also carried out to determine the extent to which IE influences IP of manufacturing firms in Kenya. The results indicate a huge proportion of change in IP is brought about by IE as indicated in table 8.

The $\mathrm{R}^{\wedge} 2$ value was 0.690 which is equivalent to $69 \%$. This implies that $69 \%$ of IP is influenced by IE. The findings concur with those of Ikeda \& Marshall (2016) who found that IE has significant influence on IP. It was also observed that operating environment grealty influences IP. The findings are also in tandem with those of Uzkurt, Kumar, Semih Kimzan, \& Eminoğlu (2013) who found that the benefits of IE allows other firms to add value through IP to an existing product where it would otherwise be difficult for one firm.

The findings indicate that an enabling IE provides an opportunity for strategic alliances, networking and collaboration. The findings are also in line with those of Engler \& Kusiak (2011) who found that market sophistication especially in manufacturing sector necessitate firms to seek collaborators to remain competitive. The findings are also in tanderm with Abosede \& Onakoya (2013) who found that collaboration with the relevant agents facilitates in the conversion of creativity from intellectual assets to IP. This is in line with Barile, Lusch, Reynoso, Saviano, \& Spohrer (2016) who found that manufacturing sector has a complex flow of information, materials and diversity of players thus firms in the sector can not operate in isolation but

Moderating Effect Of Innovation Ecosystem On Knowledge Entrepreneurship And Innovation 
rather on a comprehensive systematic collaboration. The findings concurs with those of Abosede \& Onakoya (2013) who found that collaboration with the relevant agents facilitate in the conversion of creativity from intellectual assets to IP. The operating environment should therefore be improved to raise IP in manufacturing firms in Kenya.

The normality test of data for both IE and IP was done through the levene's statistics. The p value was zero as indicated in table 4.26 which is less than 0.05 hence there is a difference between IE and IP.

This implies that the IE and IP do not measure the same characteristics and hence the normality of data is confirmed. The next step was to find the Multicollinearity between KE and IE. This is important because Multicollinearity weakens the precision power of a statistical regression model. The Multicollinearity test was conducted through the application of Variance Inflation Factor (VIF) and the level of tolerance. The results produced a VIF of 3.98 and a tolerance value of 0.254 as indicated in Table 10 .

The VIF is 3.98 which is less than the cut-off point of 10 and fall between 1 and 5 implying a moderate Multicollinearity which does not require a corrective action. The tolerance value was 0.254 which is greater than the required threshold of 0.10 indicating the absence of Multicollinearity. The findings are in tandem with Mohd Suki \& Mohd Suki (2015) who found that a VIF of less than 10 and tolerance value of between 0 and 1 does not warrant any action.

The next step was to determine the moderating effect of IE between KE and IP. This was done using the hierarchical moderated multiple regression. This was done through a three steps process while at the same time monitoring the change in the value of $\mathrm{R}$ square. The first step was to observe the relationship between $\mathrm{KE}$ and IP without IE. This was done by running a linear regression between KE and IP as indicated earlier in table 4.7 where the $\mathrm{R}$ square value was 0.675 . The second step was to observe the relationship between IE and IP without KE. The value of R square was 0.689 . The two steps imply that both KE and IE contribute to a large proportion of IP by $67.5 \%$ and $68.9 \%$ respectively. This means that both KE and IE influence IP independently. The coefficient of IE was then derived by running a linear regression between IE and IP without KE. The results indicated a value of 0.654 as indicated in table 11 .

This implies that which means that IP is expected to increase by 0.654 when IE increases by a unit holding KE constant. This led to the development of the second model which is; .

The third step was to find the interaction term between KE and IE. The interaction term was obtained by multiplying the aggregate value of KE and IE whose product was KEIE. The value of KEIE was then regressed against IP to find out whether there was a significant change in the value of $\mathrm{R}$ square with step 1 and step 2 . The resultant $\mathrm{R}$ square value was 0.753 as indicated in table 12 .

This implies that when both $\mathrm{KE}$ and IE are combined, the $\mathrm{R}$ square value increased to $75.2 \%$. It therefore means that combined effect of KE and IE (KEIE) improved the contribution of KE and IE to IP by $7.8 \%$ and $6.4 \%$ respectively. This confirms the moderating effect of IE between KE and IP.

It also means that interaction of KE and IE contributes $75.2 \%$ of IP while the remaining $24.8 \%$ is explained by other factors not captured in this study. The findings are consistent with those of Malek, Mearns and Dahlan A. Malek, Mearns, \& Flin (2010) who found that hierarchical moderated multiple regression can be used to find out whether two sets of independent variables contributes to an increase in dependent variable by testing for changes in $\mathrm{R}$ square. Multiple regression has shown that openness, autonomy, integration and experimentation capacities have a significant influence on IP (Chang, Chang, Chi, Chen, \& Deng, 2012).

The coefficient of KEIE was then derived by running a linear regression between KEIE and IP. The results indicated a value of 0.104 as indicated in table 13 .

The coefficient value of KEIE was 0.104 implying that IP is expected to increase by 0.104 when KEIE increases by a unit. This led to the development if the third model which is; . The estimated regression function is therefore; . The sum of the coefficient of KE, IE and KEIE is 0.912 which is greater than 0.900 implying that the model is adequate in measuring the moderating effect of IE on KE and IP. This is consistent with Wahyono (2018) who found that the goodness of fit index greater than 0.900 indicates a good model. This confirms that IE is a quasi-moderator because it relates and interacts with the predictor variable (Nandakumar, Ghobadian, \& O’Regan, 2010).

The magnitude of IE was quantified to determine whether the moderation effect was small, medium or large. This was measured by the effect size formula as propounded by Cohen (1988) which state that effect size; $f^{\wedge} 2=\left(R^{\wedge} 2\right.$ Inclusive $-R^{\wedge} 2$ Exclusive $) /\left(1-R^{\wedge} 2\right.$ Inclusive $)$, where the benchmark is that if $f^{\wedge} 2$ is 0.02 , the effect is small, if $f^{\wedge} 2$ is 0.15 the effect is medium and when $f^{\wedge} 2$ is 0.35 the effect is large. The effect size is therefore $\quad(0.752-0.675) /(1-0.752)=(0.077) / 0.248=0.315$. The magnitude of IE is between 0.02 and 0.35 but more nearer to 0.35 than 0.02 . This implies that IE has a large moderating effect between KE and IP.

It was therefore found that IE has a moderating effect between KE and IP. The finding is consistent with that of Oke (2013) who found that IE has a positive influence on IP and has a moderating effect on KE and IP. The finding also concurs with those of Wang, Yeung, \& Zhang (2011) who found that collaborations

Moderating Effect Of Innovation Ecosystem On Knowledge Entrepreneurship And Innovation 
in IE moderates the influence of IP in a situation of environmental uncertainty. The findings also concur with those of Naranjo Valencia, Sanz Valle, \& Jiménez Jiménez (2010) who found that there is need to introduce moderating variables when examining the relationship between KE and IP. The findings are also in line with Sadegh Sharifirad \& Ataei (2012) who found out the need for introducing the moderating variable between OC and IP. The findings are also consistent with Uzkurt, Kumar, Semih Kimzan, \& Eminoğlu (2013) who found there is need to include the environmental context which can be described as IE in establishing the relationship between KE and IP. The findings asre also in tandem with Anning-Dorson (2017) who found that $\mathrm{KE}$ is shaped by the operating environment and hence it is important to consider the contexts in which a firm is operating.

\section{CONCLUSION}

It is concluded that IE has a great moderating effect between KE and IP in manufacturing firms in Kenya. Knowledge entrepreneurship coupled with the appropriate IE is crucial for an improved IP. The interphase between KE and IE should be enhanced for improved IP of manufacturing firms in Kenya. There is need to investigate the nature and effects of tension that emanates as a result of knowledge leakage that occurs during interactions with the various players within the IE.

\section{ACKNOWLEDGMENTS}

I recognise and appreciate the grant from National Research Fund of Kenya which enabled the principle researcher (Isaac Muiruri Gachanja) to carry out the research. I also appreciate the cooperation accorded by the management of manufacturing firms participating in the study for their time and patience.

\section{REFERENCES}

Abosede, A. J., \& Onakoya, A. B. (2013). Intellectual Entrepreneurship: Theories, Purpose and Challenges. International Journal of Business Administration, 4(5), 30-37. https://doi.org/10.5430/ijba.v4n5p30

Alegre, J., Lapiedra, R., \& Chiva, R. (2006). A measurement scale for product innovation performance. European Journal of Innovation Management, 9(4), 333-346. https://doi.org/10.1108/14601060610707812

Andreeva, T., \& Kianto, A. (2011). Knowledge processes, knowledge-intensity and innovation: a moderated mediation analysis. Journal of Knowledge Management, 15(6), 1016-1034. https://doi.org/10.1108/13673271111179343

Anning-Dorson, T. (2017). Moderation-mediation effect of market demand and organization culture on innovation and performance relationship. Marketing Intelligence \& Planning, 35(2), 222-242. https://doi.org/10.1108/MIP-04-2016-0066

Atandi, F. G., Bwisa, H. M., \& Sakwa, M. (2016). Technological Innovation as entrepreneurial Determinant affecting Savings Mobilization among Micro and Small Enterprises in Kenya. International Journal of Academic Research in Business and Social Sciences, 6(3). https://doi.org/10.6007/IJARBSS/v6-i3/2059

Barile, S., Lusch, R., Reynoso, J., Saviano, M., \& Spohrer, J. (2016). Systems, networks, and ecosystems in service research. Journal of Service Management, 27(4), 652-674. https://doi.org/10.1108/JOSM-092015-0268

Brem, A. (2011). Linking innovation and entrepreneurship \&amp;ndash; literature overview and introduction of a process-oriented framework. International Journal of Entrepreneurship and Innovation Management, 14(1), 6. https://doi.org/10.1504/IJEIM.2011.040820

Cao, Y., \& Zhao, L. (2013). Analysis of patent management effects on technological innovation performance. Baltic Journal of Management, 8(3), 286-305. https://doi.org/10.1108/BJOM-May-20120033

Chang, Y.-C., Chang, H.-T., Chi, H.-R., Chen, M.-H., \& Deng, L.-L. (2012). How do established firms improve radical innovation performance? The organizational capabilities view. Technovation, 32(7-8), 441-451. https://doi.org/10.1016/j.technovation.2012.03.001

Chen, Y.-S., Lin, M.-J. J., \& Chang, C.-H. (2009). The positive effects of relationship learning and absorptive capacity on innovation performance and competitive advantage in industrial markets. Industrial Marketing Management, 38(2), 152-158. https://doi.org/10.1016/j.indmarman.2008.12.003 
Creswell, J. W. (2014). Research design: Qualitative, quantitative and mixed method approaches. (4th ed.). California: SAGE Publications, Inc.

Dahlan A. Malek, M., Mearns, K., \& Flin, R. (2010). Stress and psychological well-being in UK and Malaysian fire fighters. Cross Cultural Management: An International Journal, 17(1), 50-61. https://doi.org/10.1108/13527601011016907

Denscombe, M. (2008). Communities of Practice. Journal of Mixed Methods Research, 2(3), $270-283$. https://doi.org/10.1177/1558689808316807

Dutta, S., Lanvin, B., \& Wunsch-Vincent, S. (2015). The Global Innovation Index 2015 Effective Innovation Policies for Development. Retrieved from World Intellectual Property Organization website: https://www.wipo.int/edocs/pubdocs/en/wipo_gii_2015.pdf

Dvir, R., \& Pasher, E. (2004). Innovation engines for knowledge cities: an innovation ecology perspective. Journal of Knowledge Management, 8(5), 16-27. https://doi.org/10.1108/13673270410558756

Engler, J., \& Kusiak, A. (2011). Modeling an Innovation Ecosystem with Adaptive Agents. International Journal of Innovation Science, 3(2), 55-68. https://doi.org/10.1260/1757-2223.3.2.55

Ikeda, K., \& Marshall, A. (2016). How successful organizations drive innovation. Strategy \& Leadership, 44(3), 9-19. https://doi.org/10.1108/SL-04-2016-0029

Lau, A. K. W., \& Lo, W. (2015). Regional innovation system, absorptive capacity and innovation performance: An empirical study. Technological Forecasting and Social Change, 92, 99-114. https://doi.org/10.1016/j.techfore.2014.11.005

Leavy, B. (2012). Interview - Ron Adner: managing the interdependencies and risks of an innovation ecosystem. Strategy \& Leadership, 40(6), 14-21. https://doi.org/10.1108/10878571211278840

Majava, J., Leviäkangas, P., Kinnunen, T., Kess, P., \& Foit, D. (2016). Spatial health and life sciences business ecosystem: a case study of San Diego. European Journal of Innovation Management, 19(1), 26-46. https://doi.org/10.1108/EJIM-01-2015-0003

Mohd Suki, N., \& Mohd Suki, N. (2015). Consumers' environmental behaviour towards staying at a green hotel. Management of Environmental Quality: An International Journal, 26(1), 103-117. https://doi.org/10.1108/MEQ-02-2014-0023

Nandakumar, M. K., Ghobadian, A., \& O’Regan, N. (2010). Business-level strategy and performance. Management Decision, 48(6), 907-939. https://doi.org/10.1108/00251741011053460

Naranjo Valencia, J. C., Sanz Valle, R., \& Jiménez Jiménez, D. (2010). Organizational culture as determinant of product innovation. European Journal of Innovation Management, 13(4), 466-480. https://doi.org/10.1108/14601061011086294

Oke, A. (2013). Linking manufacturing flexibility to innovation performance in manufacturing plants. International Journal of Production Economics, 143(2), 242-247. https://doi.org/10.1016/j.ijpe.2011.09.014

Poikola, A., Kola, P., \& Hintikka, K. A. (2011). Public Data: An Introduction To Opening Information Resources. Retrieved from Ministry Of Transport and Communications website: https://julkaisut.valtioneuvosto.fi/bitstream/handle/10024/78201/Public_data__an_introduction_to_opening_information_resources.pdf?sequence $=1$

Rosnani, J., Soaib, A., \& Babak, Z. (2010). The factors in influencing knowledge entrepreneurship in Malaysia manufacturing companies. Journal of US-China Public Administration, 7(4), 86-95.

Sadegh Sharifirad, M., \& Ataei, V. (2012). Organizational culture and innovation culture: exploring the relationships between constructs. Leadership \& Organization Development Journal, 33(5), 494-517. https://doi.org/10.1108/01437731211241274

Sambuli, N., \& Whitt, J. P. (2017). Technology innovation hubs and policy engagement. Sussex.

Senges, M. (2007). Knowledge Entrepreneurship In Universities. Universitat Oberta de Catalunya.

Sotarauta, M., \& Pulkkinen, R. (2011). Institutional Entrepreneurship for Knowledge Regions: In Search of a Fresh Set of Questions for Regional Innovation Studies. Environment and Planning C: Government and Policy, 29(1), 96-112. https://doi.org/10.1068/c1066r

Uzkurt, C., Kumar, R., Semih Kimzan, H., \& Eminoğlu, G. (2013). Role of innovation in the relationship between organizational culture and firm performance. European Journal of Innovation Management, 16(1), 92-117. https://doi.org/10.1108/14601061311292878

Wahyono, W. (2018). The moderation effect of customer orientation variable on the influence of professional competence toward the quality of strategy implementation. International Journal of Law and Management, 60(6), 1432-1447. https://doi.org/10.1108/IJLMA-10-2017-0247

Wang, L., Yeung, J. H. Y., \& Zhang, M. (2011). The impact of trust and contract on innovation performance: The moderating role of environmental uncertainty. International Journal of Production Economics, 134(1), 114-122. https://doi.org/10.1016/j.ijpe.2011.06.006

Yamane, T. (1967). STATISTICS; An Introductory Analysis (2nd ed.). New York: New York University.

Moderating Effect Of Innovation Ecosystem On Knowledge Entrepreneurship And Innovation

Performance Of Manufacturing Firms In Kenya

Isaac Muiruri Gachanja, Stephen Irura Nganga, Lucy Maina Kiganane

Page | 244 
Zelaya-Zamora, J., \& Senoo, D. (2013). Synthesizing seeming incompatibilities to foster knowledge creation and innovation. Journal of Knowledge Management, 17(1), 106-122. https://doi.org/10.1108/13673271311300822

Zhang, J., Di Benedetto, C. A., \& Hoenig, S. (2009). Product Development Strategy, Product Innovation Performance, and the Mediating Role of Knowledge Utilization: Evidence from Subsidiaries in China. Journal of International Marketing, 17(2), 42-58. https://doi.org/10.1509/jimk.17.2.42

\section{FIQURES}

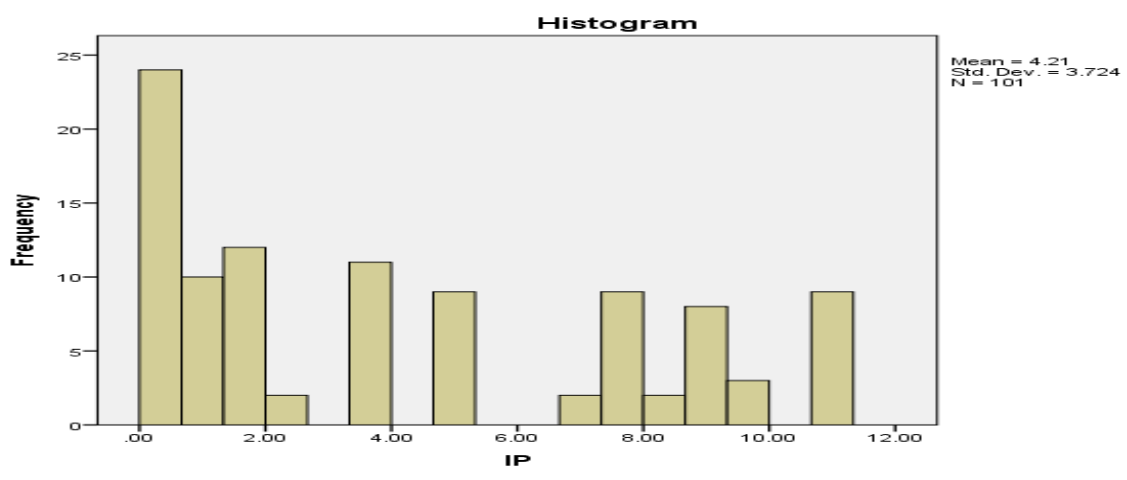

Figure 1: The distribution of IP in the manufacturing firms

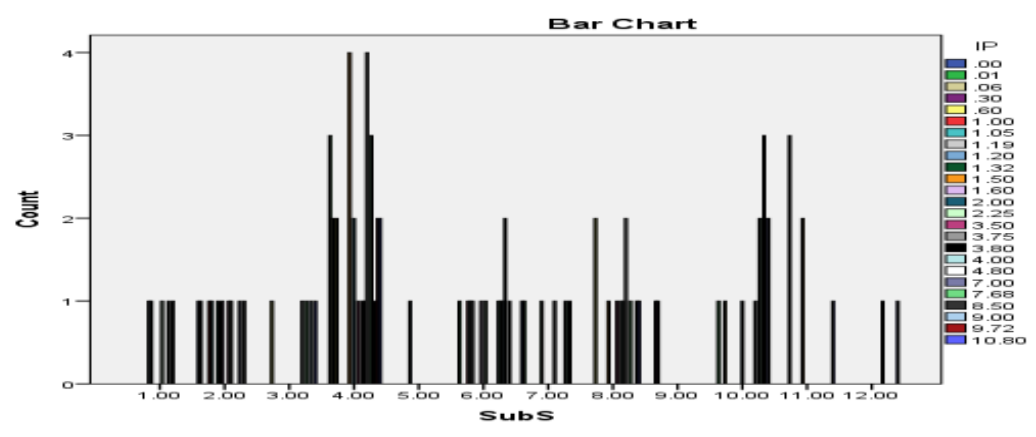

Figure 2: The comparison of IP in the manufacturing subsectors

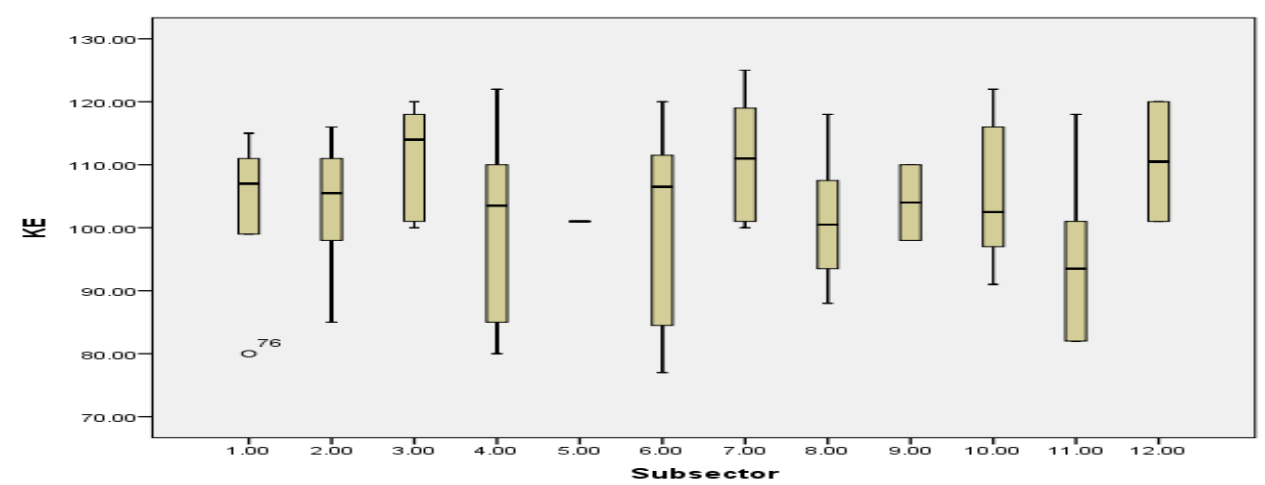

Figure 3: Comparison of manufacturing subsectors' scores on KE in Kenya 


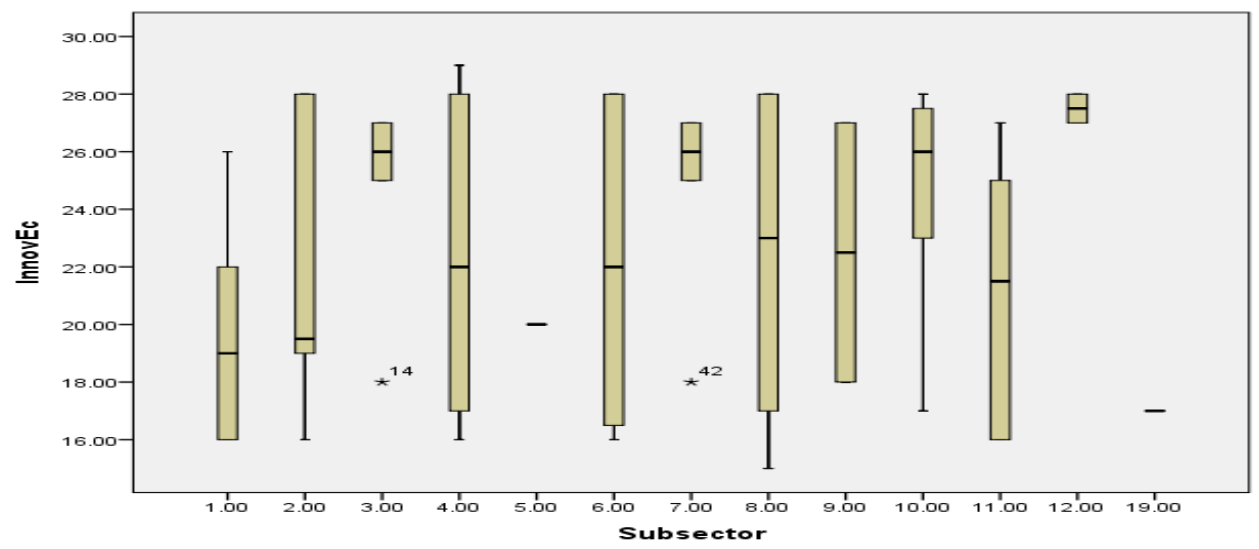

Figure 4: Comparison of manufacturing subsectors' scores on IE in Kenya

TABLES

Table 1. The Cronbach's Apha values for each of KE parameters

\begin{tabular}{clrc}
\hline & Parameter & $\begin{array}{c}\text { Cronbach's } \\
\text { Alpha }\end{array}$ & \multicolumn{2}{c}{$\begin{array}{c}\text { Number of } \\
\text { items }\end{array}$} \\
\hline i & Organisation Learning & 0.901 & 7 \\
ii & Organisation Culture & 0.898 & 7 \\
iii & Leadership & 0.905 & 6 \\
iv & Information, Communication and & 0.901 & 7 \\
& Technology & & \\
\hline
\end{tabular}

Table 2. The Relative Strength of each of the Parameters of KE on IP

\begin{tabular}{lccccc}
\hline \multicolumn{1}{c}{ Model } & $\mathrm{R}$ & $\mathrm{R}$ Square & Adjusted R Square & Std. Error of the Estimate \\
\hline i Organization learning & $.768^{\mathrm{a}}$ & .590 & .589 & & 2.47322 \\
ii. Organization Culture & $.810^{\mathrm{a}}$ & .657 & .655 & & 2.26418 \\
iii Leadership & $.802^{\mathrm{a}}$ & .643 & .642 & 2.30788 & \\
iv ICT & $.785^{\mathrm{a}}$ & .617 & .616 & & 2.39128 \\
\hline
\end{tabular}

Table 3. The Significance Level of each of the Parameters of KE on IP

\begin{tabular}{|c|c|c|c|c|c|c|}
\hline \multirow{2}{*}{\multicolumn{2}{|c|}{ Model }} & \multicolumn{2}{|c|}{ Unstandardized Coefficients } & \multirow{2}{*}{$\begin{array}{l}\text { Standardized Coefficients } \\
\text { Beta }\end{array}$} & \multirow[t]{2}{*}{ t } & \multirow[t]{2}{*}{ Sig. } \\
\hline & & B & Std. Error & & & \\
\hline \multirow{5}{*}{1} & (Constant) & -11.316 & .651 & & & .000 \\
\hline & $\mathrm{OL}$ & -.088 & .074 & -.126 & -1.193 & .234 \\
\hline & $\mathrm{OC}$ & .282 & .089 & .399 & 3.173 & .002 \\
\hline & Leadership & .236 & .072 & .301 & 3.263 & .001 \\
\hline & ICT & .195 & .055 & 279 & 3.542 & .000 \\
\hline
\end{tabular}

Table 4.The Coefficients of Regression between of KE and IP

\begin{tabular}{|c|c|c|c|c|c|c|}
\hline \multirow{2}{*}{\multicolumn{2}{|c|}{ Model }} & \multicolumn{2}{|c|}{$\begin{array}{l}\text { Unstandardized } \\
\text { Coefficients }\end{array}$} & $\begin{array}{l}\text { Standardized } \\
\text { Coefficients }\end{array}$ & \multirow[t]{2}{*}{$\mathrm{t}$} & \multirow[t]{2}{*}{ Sig. } \\
\hline & & B & Std. Error & Beta & & \\
\hline 1 & $\begin{array}{l}\text { (Constant) } \\
\text { KE }\end{array}$ & $\begin{array}{r}-11.479 \\
.154\end{array}$ & $\begin{array}{l}.656 \\
.006\end{array}$ & .822 & $\begin{array}{r}-17.486 \\
24.426\end{array}$ & .000 \\
\hline
\end{tabular}

Table 5. Regression analysis between Knowledge Entrepreneurship and Innovation Performance

\begin{tabular}{lrrrr}
\hline Model & $\mathrm{R}$ & $\mathrm{R}$ Square & $\begin{array}{c}\text { Adjusted R } \\
\text { Square }\end{array}$ & Std. Error of the Estimate \\
\hline 1 & $.822^{\mathrm{a}}$ & .675 & .674 & 2.20182 \\
\hline
\end{tabular}


Table 6 Test of Homogeneity of Variance in KE and IP

\begin{tabular}{llcccc}
\hline & Levene Statistic & df1 & df2 & Sig. \\
\hline \multirow{3}{*}{ IP } & 12.774 & 12 & 125 & .000 \\
& Based on Mean & 5.546 & 12 & 125 & .000 \\
& Based on Median & 5.546 & 12 & 69.841 & .000 \\
Based on Median and with adjusted df & 11.798 & 12 & 125 & .000 \\
\hline
\end{tabular}

Table 7. Linear Regression between the Parameters of IE and IP without KE

\begin{tabular}{lcccc} 
Model & $\mathrm{R}$ & $\mathrm{R}$ Square & $\begin{array}{c}\text { Adjusted R } \\
\text { Square }\end{array}$ & $\begin{array}{c}\text { Std. Error of the } \\
\text { Estimate }\end{array}$ \\
\hline $\begin{array}{c}\text { Presence of accelerators and incubators } \\
\text { Availability of trade organization support }\end{array}$ & $.844^{\mathrm{a}}$ & .712 & .711 & 2.07287 \\
$\quad .811^{\mathrm{a}}$ & .657 & .656 & 2.26236 \\
Technology spill over & $.809^{\mathrm{a}}$ & .654 & .653 & 2.27216 \\
Availability of business services & $.786^{\mathrm{a}}$ & .618 & .617 & 2.38701 \\
Dynamic networking & $.782^{\mathrm{a}}$ & .611 & .610 & 2.40980 \\
Infrastructural support & $.818^{\mathrm{a}}$ & .611 & .669 & 2.22004 \\
\hline
\end{tabular}

Table 8. Regression analysis between Innovation Ecosystem and Innovation Performance

\begin{tabular}{|c|c|c|c|c|c|c|c|c|}
\hline Model & $\mathrm{R} \quad R^{2}$ & $\begin{array}{c}\text { Adjusted } \\
R^{2}\end{array}$ & $\begin{array}{l}\text { Std. Error of the } \\
\text { Estimate }\end{array}$ & $\begin{array}{l}\text { Change Statistics } \\
R^{2} \text { Change }\end{array}$ & F Change & df1 & df 2 & Sig. Change \\
\hline 1 & .690 & .689 & 2.14944 & .690 & 640.208 & 1 & 287 & .000 \\
\hline
\end{tabular}

Table 9: Test of Homogeneity of Variance between IE and IP

\begin{tabular}{llcccc}
\hline & Levene Statistic & df1 & df2 & Sig. \\
\hline \multirow{3}{*}{ IP } & Based on Mean & 8.371 & 14 & 261 & .000 \\
& Based on Median & 4.026 & 14 & 261 & .000 \\
& Based on Median and with adjusted df & 4.026 & 14 & 126.825 & .000 \\
Based on trimmed mean & 7.778 & 14 & 261 & .000 \\
\hline
\end{tabular}

Table 10. Multicollinearity Test between KE and IE

\begin{tabular}{|c|c|c|c|c|c|c|c|c|}
\hline \multirow[t]{2}{*}{ Model } & \multirow[b]{2}{*}{ (Constant) } & \multicolumn{2}{|c|}{ Unstandardized Coefficients } & \multirow{2}{*}{$\begin{array}{l}\text { Standardized } \\
\text { Coefficients } \\
\text { Beta }\end{array}$} & \multirow{2}{*}{$\begin{array}{l}\mathrm{t} \\
- \\
-20.009\end{array}$} & \multirow{2}{*}{$\begin{array}{l}\text { Sig. } \\
.000\end{array}$} & \multicolumn{2}{|c|}{ Collinearity Statistics } \\
\hline & & $\begin{array}{l}\mathrm{B} \\
-12.003\end{array}$ & $\begin{array}{l}\text { Std. Error } \\
.600\end{array}$ & & & & Tolerance & VIF \\
\hline 1 & $\begin{array}{l}\mathrm{IE} \\
\mathrm{KE}\end{array}$ & $\begin{array}{l}.376 \\
.077\end{array}$ & $\begin{array}{l}.048 \\
.011\end{array}$ & $\begin{array}{l}.477 \\
.409\end{array}$ & $\begin{array}{l}7.872 \\
6.754\end{array}$ & $\begin{array}{l}.000 \\
.000\end{array}$ & $\begin{array}{l}.254 \\
.254\end{array}$ & $\begin{array}{l}3.938 \\
3.938\end{array}$ \\
\hline
\end{tabular}

Table 11. The linear Regression between IE and IP and Coefficients of IE

\begin{tabular}{|c|c|c|c|c|c|c|}
\hline \multirow[t]{2}{*}{ Model } & & \multicolumn{2}{|c|}{ Unstandardized Coefficients } & Standardized Coefficients & \multirow[t]{2}{*}{$\mathrm{t}$} & \multirow[t]{2}{*}{ Sig. } \\
\hline & & B & Std. Error & Beta & & \\
\hline 1 & (Constant) & -10.402 & .592 & & -17.561 & .000 \\
\hline 1 & IE & .654 & .026 & .831 & 25.302 & .000 \\
\hline
\end{tabular}

Table 12. The R Square value for Regression between KEIE and IP

\begin{tabular}{ccccc}
\hline Model & $\mathrm{R}$ & $\mathrm{R}$ Square & Adjusted R Square & Std. Error of the Estimate \\
\hline 1 & $.868^{\mathrm{a}}$ & .753 & .752 & 1.92071 \\
\hline
\end{tabular}

Table 13. linear Regression between KEIE and IP and its Coefficients

\begin{tabular}{lrccrr}
\hline Model & \multicolumn{2}{c}{ Unstandardized Coefficients } & Standardized Coefficients & t & Sig. \\
\cline { 2 - 4 } (Constant) & $\mathrm{B}$ & Std. Error & Beta & & \\
KEIE & -4.528 & .317 & & -14.268 & .000 \\
& .104 & .000 & .868 & 29.567 & .000 \\
\hline
\end{tabular}

